\title{
HEADING TOWARDS THREAT OF RESISTANT SUPER BUG.... CURRENT PATTERN OF ANTIMICROBIAL SENSITIVITY TO SALMONELLA TYPHI IN KARACHI.
}

\footnotetext{
1. MBBS, FCPS

Associate Professor Medicine

Dow University of Health Sciences, Karachi.

2. MBBS, FCPS

Associate Professor Medicine

Dow University of Health Sciences, Karachi.

3. MBBS

Medical Officer

Mamji Hospital Karachi.

4. BE

Assistant Professor

NED.

5. MBBS

Medical Officer

Lifeline Medical Centre Karachi.
}

Correspondence Address:

Dr. Saiyeda Naeyma Zehra Rizvi

Medical Officer

Lifeline Medical Centre Karachi.

drnayemarizivi@gmail.com

Article received on:

02/12/2019

Accepted for publication:

07/02/2020
Syed Tahseen Akhtar ${ }^{1}$, Iftikhar Haider Naqvi ${ }^{2}$, Owais Khan ${ }^{3}$, Syed Tauqeer Ahmed Hasmi ${ }^{4}$, Saiyeda Nayema Zehra Rizvi ${ }^{5}$

ABSTRACT... Objectives: The present study was aimed to find out the prevalence of MDR and XDR Typhoid and the remaining or alternate treatment options here in Karachi. Study Design: Descriptive retrospective analytical study. Setting: Department of Medicine, at Mamji Hospital Karachi. Period: From Jan 2019 till July 2019. Material \& Methods: The medical records of all the patient admitted, were reviewed by the department of Medicine, at Mamjee Hospital Karachi specifically diagnosed to have Typhoid fever during the period between Jan 2019 till July 2019. A total of 72 patients were included in this study. Chart reviews were used to obtain and later collect the data. Typhoid was confirmed over Blood culture yielding Salmonella typhi. Demographic data and pattern of antibiotic sensitivity were collected. Statistical analysis was performed on SPSS version 17. Continuous variables were expressed as mean \pm SD. Discrete variables were expressed as percentages and proportions. Results: From January 2019 till July 2019, 72 patients were diagnosed to have Typhoid fever (Salmonella Typhi culture positive) of which $43(60 \%)$ were male and majority of the patients were aged between 18 to 40 years $37(51 \%)$. Out of 14 antibiotics checked for sensitivity to Salmonella Typhi the Quinolones were the most resistant (85\%) antibiotics followed by Ampicillin (83\%) and Trimethoprimsulfamethoxazole (82\%). 48(66\%) among 72 patients had extended drug resistant typhoid, 14(19\%) were multidrug resistant typhoid while 11(15\%) were pan sensitive. Conclusion: Majority of the patients had extended drug resistant typhoid, whereas quite a few had multidrug resistant typhoid. Most sensitive drugs were Imipenem, meropenem and Azithromycin whereas Quinolones along with other agents were found to have most resistance against Salmonella Typhi.

Key words: $\quad$ Culture and Sensitivity, Extended Resistant Typhoid, Multi Drug Resistance.

Article Citation: Akhtar ST, Naqvi IH, Khan O, Hashmi STA, Rizvi SNZ. Heading towards threat of resistant super bug.... current pattern of antimicrobial sensitivity to salmonella typhi in Karachi. Professional Med J 2020; 27(5):1070-1073. DOI: 10.29309/TPMJ/2020.27.05.4389

\section{INTRODUCTION}

Since the invention of antibiotics in the first half of last century we had gone through era of antibiotic resistance but fortunately owing to introduction of new groups of antibiotic we did not face big challenges. Now the threat of resistance is increasing day by day and there is a significant reduction in the introduction of novel class of antibiotics, thus we have entered into a period of multidrug resistant to extended drug resistant superbugs. ${ }^{1,2}$

Salmonella Typhi causes typhoid fever, a lifethreatening illness. An estimated 11-20 million people get sick from typhoid and between $1,28,000$ and $1,61,000$ people die due to this infection every year. ${ }^{3-7}$

Strains of Salmonella Typhi which are resistant to the first-line treatment options (ampicillin, chloramphenicol, and trimethoprimsulfamethoxazole) and the second-line options (fluoroquinolones) have become a major public health concern in Pakistan and the rise of these strains have developed resistance even against ceftriaxone among patients with typhoid infection. The emergence of this ceftriaxone resistant strain has severely constrained the treatment options. ${ }^{8}$

Typhoid is a frequent infection in poor under developed countries where pure drinking water and sanitation is still a dream. Pakistan is one of 
those countries where typhoid prevalence even on this day, is very high. Pakistani Health Authorities have reported an ongoing outbreak of extensively drug resistant (XDR) typhoid fever that began in the Hyderabad district of Sindh province in November 2016. Provincial Disease Surveillance and Response Unit (PDSRU) of Sindh, Pakistan has reported 5274 cases of XDR typhoid among 8188 overall cases of typhoid fever in a period of 2 years (From 2016 to 2018). It is of note that most of cases $(69 \%)$ percent were reported in Karachi only (the capital city of Sindh). ${ }^{9}$

Extended drug resistant typhoid fever (XDRTF) is defined as typhoid fever caused by Salmonella Enterica serovar Typhi strains (Typhi), which are resistant to all recommended antibiotics for typhoid that is first and second-line drugs and third generation cephalosporins. ${ }^{9}$

Multidrug-resistant typhoid fever (MDRTF) is defined as typhoid fever caused by Salmonella enterica serovar. Typhi strains (S.Typhi), which are resistant to the first-line recommended drugs for treatment such as chloramphenicol, ampicillin and trimethoprim-sulfamethoxazole. ${ }^{10}$

The current study was aimed to determine the frequency of MDR and XDR Typhoid and the remaining or alternate treatment options here in Karachi.

\section{MATERIAL \& METHODS}

We reviewed the medical records of all patients admitted by the department of Medicine, in Mamji Hospital Karachi with the diagnosis of Typhoid during the period between Jan 2019 till July 2019. All information was obtained by chart reviews. Typhoid was confirmed over Blood culture yielded Salmonella typhi. Demographic data and pattern of antibiotic sensitivity were collected. Statistical analysis was performed on SPSS version 17. Continuous variables were expressed mean \pm SD. Discrete variables were expressed as percentages and proportions.

\section{RESULTS}

From January 2019 till August 2019, seventy-two (72) patients were confirmed of having typhoid fever through blood culture growth of salmonella typhi. Data was collected and analyzed where out of 72 patients, $43(60 \%)$ were male. Age of subjects ranged from 13-72 years with a mean of $23.35 \pm 12.11$ where most patients were young (Table-I).

\begin{tabular}{|l|c|}
\hline \multicolumn{1}{|c|}{ Age Group } & No. of Patients (\%) \\
\hline Less than 18 & $30(42 \%)$ \\
\hline 18 to 40 & $37(51 \%)$ \\
\hline Above 40 & $5(7 \%)$ \\
\hline \multicolumn{2}{|c|}{ Table-I. Typhoid in different age groups. } \\
\hline
\end{tabular}

A total of 14 antibiotics including first line drugs (Chloramphenicol, Ampicillin and Trimethoprimsulfamethoxazole) Ciprofloxacin, Ceftriaxone and others were checked for sensitivity. The Quinolones group including Ciprofloxacin and Levofloxacin were the most resistant (85\%) antibiotics followed by Ampicillin (83\%) and Trimethoprim-sulfamethoxazole (82\%) among the list. Imipenem is sensitive in all cases while Meropenem and Azithromycin was resistant in only one case (Figure-1).

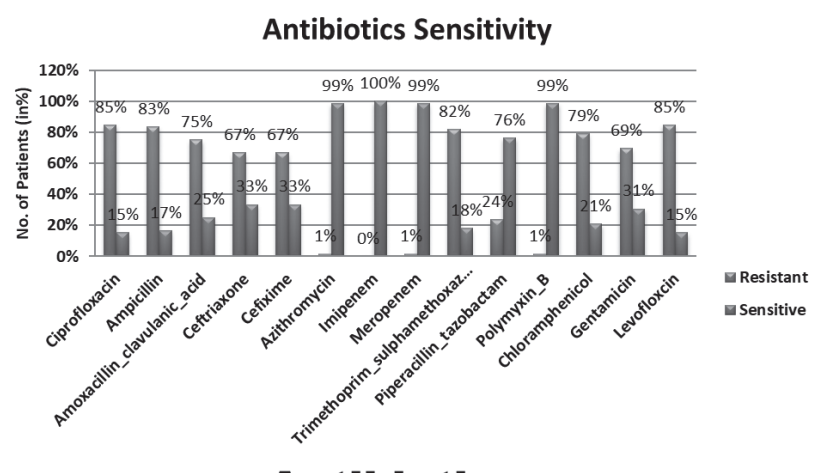

\section{Antibiotics}

Figure-1. Antibiotics sensitivity in typhoid

\section{DISCUSSION}

Typhoid is a life-threatening infectious disease caused by Salmonella typhi. It is a major public health issue in Pakistan especially in Sindh where 8188 typhoid cases were reported during a period between November 2016 to December 2018 and out of which 5274(64.4\%) were XDR typhoid and $69 \%$ of these cases were from Karachi alone. ${ }^{9}$ Since then there has been no shift of this trend and we found similar results in 
our retrospective study done at Mamjee Hospital Karachi from January 2019 till August 2019. Cases of XDR Typhoid were almost in similar numbers (66\%) as quoted in WHO report. ${ }^{9}$ WHO/ EMRO in their recent bulletin has reported that Pakistan is experiencing a continuous heave of XDR Typhi since 2016. Current statistics as reported on August 2019, 23 districts of Sindh province have reported 10,365 cases of XDR typhoid where district Karachi (67\%) was found to be the most affected one. At present cases of XDR typhoid prevalence in Karachi continue to present with the same rate as previous couple of years. This is an alarming picture not only for Pakistan but globally as well. Our study observed $19 \%$ similar patterns of MDR typhoid cases when compared to other studies ${ }^{11-14}$ while Pan-sensitive typhoid cases were reported to be just $15 \%$ in our study subjects.

In our study, sensitivity or susceptibility to around 14 antibiotics was checked. Ciprofloxacin and levofloxacin were identified as most resistant antibacterials (85\%), which is way higher than the choudhury MAJ et al ${ }^{15}$ Laghari G et al $^{16}$ reported $60.9 \%$ and $65.8 \%$ sensitivity for Cefixime and ceftriaxone respectively. After the emergence of first line antibiotic resistance, Ciprofloxacin was declared as drug of choice in typhoid and was found to be sensitive in $100 \%$ cases throughout the last decade of previous century in Pakistan ${ }^{17}$, but currently, most of typhoid cases are resistant to this particular antibiotic which is a distressing sign because with poor and limited resources in a country like Pakistan, economical antibiotic is surely a blessing.

First line antibiotics for typhoid Ampicillin, Chloramphenicol and Trimethoprimsulphamethoxazole are not being prescribed commonly in Pakistan due to resistance and same did our study showed high percentages of resistance than MAJ et al. ${ }^{15}$ Cefixime and Ceftriaxone are most prescribed antibiotics among Typhoid cases in Pakistan but unfortunately our results showed a high number of resistant cases quite similar to MAJ et al. ${ }^{15}$ although are drugs not usually prescribed in cases of typhoid fever showed highest sensitivity against salmonella and now almost all cases of XDR typhoid are being treated with these antibiotics as also mentioned in WHO report. ${ }^{9}$ This is an alarming situation because our options are getting narrowed down and Carbapenems are going to be the only IV option available at hand after the ones mentioned above. ${ }^{18,19}$

The issues are mounting day by day and need to be addressed immediately to prevent the spread of this life threatening XDR typhoid beyond Sindh. In this regard, vaccination, public health education, safe drinking water and emphasis on hygiene all over Sindh has to be taken promptly as well as seriously for the resolution of this pertinent issue.

\section{CONCLUSION}

Majority of the patients had extended drug resistant typhoid whereas quite a few had multi drug resistance typhoid. Most sensitive drugs were imipenem, meropenem and Azithromycin whereas quinolones along with other agents were found to have most resistance against salmonella typhi.

\section{Copyright $(27$ Feb, 2020.}

\section{REFERENCES}

1. O'Neill J. Tackling drug-resistant infections globally: Final report and recommendations. Review of antimicrobial resistance. London: HM Government and Wellcome trust; 2016.

2. World Health Organization. Antimicrobial resistance: Global report on surveillance. Geneva: World Health Organization; 2014.

3. Typhoid www.who.int/news-room/fact-sheets/detail/ typhoid.

4. WHO. Typhoid: Key facts. [Internet]. WHO. [cited 2018 Mar 19]. Available from: https://www.who.int/ mediacentre/factsheets/typhoid/en/.

5. Antillón M, Warren JL, Crawford FW, Weinberger DM, et al. The burden of typhoid fever in low- and middleincome countries: A meta regression approach. PLoS Negl Trop Dis 2017; 11(2): e0005376.

\section{Azithromycin, Meropenem and Imipenem}


6. Mogasale V, Maskery B, Ochiai RL, Lee JS, Mogasale VV, Ramani E, et al. Burden of typhoid fever in low income and middle income countries: A systematic, literature based update with risk factor adjustment. Lancet Glob Health 2014; 2(10): e570-80.

7. Radha krishnan A, Als D, Mintz ED, Crump JA, Stanaway $\mathrm{J}$, Breiman RF, et al. Introductory article on global burden and epidemiology of typhoid fever. Am J Trop Med Hyg 2018; 99(3 Suppl):4-9.

8. Study: XDR typhoid in Pakistan carries added resistance genes. www.cidrap.umn.edu/newsperspective/2018/02/study-xdr.

9. WHO | Typhoid fever - Islamic Republic of Pakistan. www.who.int/csr/don/27-december-2018-typhoid.

10. Kumar R, Gupta N, Shalini. Multidrug-resistant typhoid fever. Indian J Pediatr. 2007; 74: 39-42.

11. Bhutta ZA. Impact of age and drug resistance on mortality in typhoid fever. Arch Dis Child 1996; 75:214217.

12. CM Parry. Multidrug resistant enteric fever in South Asia: unmet medical needs and opportunities. BMJ 2019; 364: k5322.

13. Rathod P, Patil P, Choure B, Patil A. Study of current prescribing pattern of antimicrobial drugs in indoor cases of enteric fever in a tertiary care hospital. Int $\mathrm{J}$ Basic Clin Pharmacol. 2016; 5:62.
14. Shaikh AA, Shaikh A, Tahir A. Antimicrobial resistance trends of typhoidal salmonellae in southern Pakistan. RMJ. 2019; 44:7-10.

15. Chowdhury MAJ, Shumy FAnam AM, Chowdhury MK. Current status of typhoid fever: A review. Bangladesh Med J. 2014 May; 43:(2).

16. Laghari GS, Hussain Z, Hussain SZ, Kumar H, Uddin SM, Haq A. Antimicrobial Susceptibility Patterns of Salmonella Species in Southern Pakistan. Cureus. 2019 Apr;11(4). DOI 10.7759/cureus.4379.

17. Akhtar MA, Hussain A, Karamat KA, Naqi N, Zubdi N. Role of ciprofloxacin in typhoid fever. JPMA. The Journal of the Pakistan Medical Association. 1992 Jan;42(1):9-10.

18. Veeraraghavan B, Pragasam AK, Bakthavatchalam YD, Ralph R. Typhoid fever: Issues in laboratory detection, treatment options and concerns in management in developing countries. Future Sci OA 2018; 4(6):FSO312.

19. Ryan ET, Andrews DJ. Treatment and prevention of enteric (typhoid and paratyphoid) fever. UpToDate. Waltham, UpToDate Inc. http://www. uptodate. com. Accessed on. 2019 Apr;22.

\begin{tabular}{|c|l|l|l|}
\hline \multicolumn{3}{|c|}{ AUTHORSHIP AND CONTRIBUTION DECLARATION } \\
\hline Sr. \# & \multicolumn{1}{|c|}{ Author(s) Full Name } & \multicolumn{1}{c|}{ Contribution to the paper } \\
\hline 1 & Syed Tahseen Akhtar & $\begin{array}{l}\text { Conceive and design the } \\
\text { idea of manuscript and did } \\
\text { final approval. } \\
\text { Did the manuscript writing. }\end{array}$ \\
2 & $\begin{array}{l}\text { Iftikhar Haider Naqvi } \\
\text { Collect the data of the } \\
\text { study. } \\
\text { Did the statistical analysis of } \\
\text { the study. } \\
\text { Collect the data. }\end{array}$ \\
\hline 5 & $\begin{array}{l}\text { Owais Khan } \\
\text { Syed Tauqeer Ahmed } \\
\text { Saiyeda Nayema Zehra } \\
\text { Rizvi }\end{array}$ & \\
\hline
\end{tabular}

